\title{
Effectiveness of Pozzolanic Leaf Ashes and Plastics on Geotechnical Characteristics
}

\author{
Vasudevan Yathushan*, Udeni Gnanapriya Anuruddha Puswewala \\ Department of Civil Engineering, Faculty of Engineering, University of Moratuwa, Sri Lanka \\ Received 14 November 2021; received in revised form 29 December 2021; accepted 30 December 2021 \\ DOI: https://doi.org/10.46604/ijeti.2022.8912
}

\begin{abstract}
This study aims to investigate the geotechnical characteristics of three soils by adding waste plastics and a mixture of leaf ashes. The soil stabilizers used in the study are the plastics strips from waste plastic file folders and a mixture of ashes from five naturally occurring pozzolanic leaves in Sri Lanka. The plastics used in this study have a width of $5 \mathrm{~mm}$ and aspect ratios of 1,2, 3, and 4 in the weight percentages $0.5,1,2,4$, and 8 . The mixture of leaf ashes used is in the weight percentages $2,4,6,8$, and 10. The investigated geotechnical characteristics of the soils include the improvement of maximum dry density (MDD), optimum moisture content (OMC), soaked California bearing ratio (CBR), shear strength parameters, plastic index (PI), and Atterberg limits. The results suggest that the optimum improvement in soaked CBR and MDD can be achieved by adding $2 \%$ plastics and $6 \%$ leaf ash mixture into the soils. Shear strength parameters and PI can also be improved.
\end{abstract}

Keywords: soil stabilization, shear strength, plastic, leaf ash, geotechnical properties

\section{Introduction}

In nature, soil deposits occur non-homogeneously, and their shear strength and bearing capacity vary widely [1]. The constructions conducted on weak or expansive soil result in structural failures due to the formation of foundation cracks, a large volume change of soil, a shift in the entire structure, and pavement buckling [2]. Hence, the engineering properties, such as the shear strength parameters of the weak foundation soil, must be adequately improved to a level suitable for construction. Moreover, with the exponential growth of population, rapid industrialization, and limited availability of lands, it is imperative to select the areas of weak soil such as agricultural lands for development works. Hence, the need for improving the stability of weak soil is vital worldwide.

There are several techniques for improving the stability of different soils, such as the drainage method, vibration method, grouting and compaction method, pre-compression method, consolidation method, etc. This work focuses on the stabilization method. Stabilization can be described as a way of altering the nature of the soils to fulfil the engineering purposes, e.g., increasing the stability, bearing capacity, and durability of the soils, decreasing the permeability, compressibility, shrinkage, and swelling of the soils, etc. [3].

The stabilization method can be divided into types, i.e., the chemical, mechanical, and polymer or alternative stabilization methods [4-6]. In mechanical stabilization, two or more soils are added and compacted to modify the physical properties such as particle size distribution, solidity, plasticity, etc. [7]. In chemical stabilization, the properties of soils are modified through the addition of traditional calcium-based agents, such as cement, lime, and bitumen, as well as nontraditional agents which are

* Corresponding author. E-mail address: yathushan.v@gmail.com

Tel.: +94-0770703230 
not fully developed to interact physically and chemically with soils [6]. In cases where mechanical stabilization cannot be used, chemical stabilization is preferred in the industry. In particular, in road construction, where there is an excess amount of moisture, cement, lime, or bituminous materials are added into soils for stabilization [8]. Both the mechanical and chemical means for soil stabilization have prevailed in the industry for a long time. The addition of innovative materials, such as polymers and alternative stabilizing materials, is known as the polymer or alternative stabilization method. Soil stabilization is mainly done for embankment construction, land reclamation, slope stabilization, and highway construction.

Although the use of stabilizing agents such as lime, cement, and certain chemicals (e.g., calcium chloride, sodium chloride, and sodium silicate) have been chronicled well, its practical application is limited in the present day [6]. Cement is very expensive. It requires high energy and can result in environmental hazards by releasing carbon dioxide. Also, the production of lime can cause climate change. Furthermore, using geogrids and geotextiles for reinforcing soil is not a cost-efficient solution for low-cost projects [4]. Therefore, there is a necessity in finding some other economical and efficient options to stabilize weak soil.

This study investigates the use of waste plastic materials and pozzolanic leaf ash mixtures for soil stabilization. The waste plastic materials used are with aspect ratios (ARs) ranging from 1 to 4 and weight percentages ranging from 0.5 to 8 . The pozzolanic leaf ash mixtures used are with different weight percentages ranging from 0 to 10 . The stabilizing potential of these selected agents is compared based on the improvement in the geotechnical characteristics, such as maximum dry density (MDD), California bearing ratio (CBR), shear strength parameters, and plastic index (PI) of the stabilized soil.

\section{Literature Review}

Out of the 8.3 billion metric tons manufactured plastics worldwide annually, generated plastic waste is around 6.3 billion metric tons. Only $9 \%$ of the waste has been recycled and the rest has been accumulated in landfills and dumped in the natural environment causing pollution to nature [9]. Hence, it is paramount to find an effective way for using plastic waste to protect the environment.

There have been very few works on the use of plastics as soil stabilizers. Thakare and Sonule [10] found out that it is possible to increase the bearing capacity of soil if plastic bottles are used in layers. Choudhary et al. [4] found that, by using 4\% plastic content with the AR of 3, soil bearing capacity and soil strength parameters can be improved. Bhattarai et al. [11] varied the weight percentages of plastics as $0,0.25,0.5$, and 1 and ARs from 1 to 4 on inorganic silt, and found the optimum weight to be $0.5 \%$ plastics with the AR of 3. Neopaney et al. [12] varied the weight percentages of plastics as 0.25 and 0.5 and ARs as 1 , 2, and 3, and found that the maximum improvement in CBR was obtained for 0.5\% plastics with the AR of 3. Kalliyath et al. [5] showed that MDD can be considered an indicator for the determination of the improved soil strength parameters.

It is evident that the results found from the previous works on using plastics as soil stabilizers are quite different from one another. Moreover, none of the above works considered a wider range of parameters such as shear strength parameters, optimum moisture content (OMC), MDD, CBR, and PI. Thus, the present work will bring a better understanding regarding this problem by considering improved shear strength parameters, MDD and the corresponding OMC, soaked CBR values, and PI.

In recent times, a few studies were conducted with bamboo leaf ashes (BLA) and banana leaf ashes (BALA). Amu and Adetuberu [8] carried out tests on three different soil samples by varying the weight percentages of BLA as 2, 4, 6, 8, and 10 to find the effectiveness of using BLA to stabilize the lateritic soil for highway construction. It was found that the addition of BLA to the soil considerably reduced OMC and PI while increasing the MDD, CBR, and shear strength parameters of the soil. Nnochiri et al. [13] and Elijah [14] investigated the use of BALA for the improvement of soil properties; out of the five different weight percentages of BALA ranging from 2 to 10, the addition of $4 \%$ BALA showed the maximum improvement in CBR and unconfined compressive strength by almost $11 \%$ and $17 \%$ respectively, compared to that of the virgin soil. 
In the past, there had been no studies showing the comparison between the stabilizing potential of plastics and a mixture of pozzolanic leaf ashes on the same soil. Also, previous studies were conducted by mixing the soil with a single kind of leaf ashes but not with a mixture of multiple kinds of ashes. Sometimes, there will be a problem of obtaining a single kind of leaf ashes in large quantity in a practical scenario. Therefore, in this study, a mixture of multiple kinds of ashes, instead of a single kind of ashes, is used to improve the geotechnical characteristics of the soil. Hence, the findings from this work will lead to better decision-making on selecting stabilizers and thus fill this important research gap. In addition to that, very few works had investigated the stabilizing potential of a selected stabilizing agent on different types of soils. The current research will address this gap by comparing the effectiveness of the selected stabilizing agents on three different soils.

\section{Materials and Methods}

\subsection{Materials}

Three different soils are collected from Kanthale area in Trincomalee District and brought to the University of Moratuwa in Sri Lanka. Plastics from waste plastic file folders are made into strips, having a width of $5 \mathrm{~mm}$ and ARs of 1, 2, 3, and 4 with the lengths $5,10,15$, and $20 \mathrm{~mm}$ respectively. The plastics used for the study are made of polypropylene with a density of $0.915 \mathrm{~g} / \mathrm{cm}^{3}$. Previous researchers found the optimum plastic content for improving soil properties to be within the range of $0.5 \%$ and $4 \%$ [4-6]. However, in this research, the scope is widened. The samples to be tested are prepared by mixing the plastics in the weight percentages ranging from 0 to $8(0.5 \%, 1 \%, 2 \%, 4 \%$, and $8 \%)$ with the selected air-dried soils to test for OMC, MDD, soaked CBR, and shear strength parameters.

Initially, seven kinds of commonly available leaves in Sri Lanka, i.e., bamboo, teak, Gliricidia sepium, Thespesia populnea, banana, neem, and mango leaves, are collected and sun-dried in an open space for one month. Then, those leaves are burnt in an open atmosphere and sieved through a $0.075 \mathrm{~mm}$ sieve. Compared to the percentage of dried leaves by weight, around $30-35 \%$ ashes are obtained. It implies that it is possible to obtain around 3-3.5 $\mathrm{kg}$ ashes from $1 \mathrm{~kg}$ dried leaves. Such ashes are tested through X-ray fluorescence (XRF) tests for their pozzolanic characteristics. Pozzolana is a siliceous material that does not show any cementitious property in nature; however, with the presence of water, in finely divided form, it displays cementitious property by reacting with $\mathrm{Ca}(\mathrm{OH})_{2}[15]$. The leaf ashes which possess the pozzolanic characteristics are mixed in equal quantity by weight. The mixture of leaf ashes in the weight percentages $2,4,6,8$, and 10 will then be mixed with the selected air-dried soils to study its effectiveness as a soil stabilizer.

\subsection{Experimental methods}

Fig. 1 illustrates the summary of the experiments performed in the study. Initially, particle size distribution tests are carried out as per ASTM D6913/D6913M, followed by Atterberg limit tests according to ASTM D4318 [16-17]. From the results of particle size distribution and Atterberg limit tests, soil types are classified according to the unified soil classification system (USCS). Though it is possible to get a good response for the experiments done with ashes as additives, it is not possible to conduct Atterberg limit tests on the soils with large plastic pieces having the ARs of 3 and 4 and lengths of 15 and 20 mm. Hence, Atterberg limit tests are conducted for the soils with the ashes in different percentages only.

It is found that modern applications require a larger compacting effort than that obtained from the standard Proctor compaction test. Hence, the modified Proctor compaction test is preferred in this research. The plastics with four different ARs in five different weight percentages as well as the ashes in five different weight percentages are added to the soils. The modified Proctor compaction tests are carried out to determine the improved OMC and MDD as per ASTM D1557 [18]. Fig. 2 shows the setup of the modified Proctor compaction tests. 


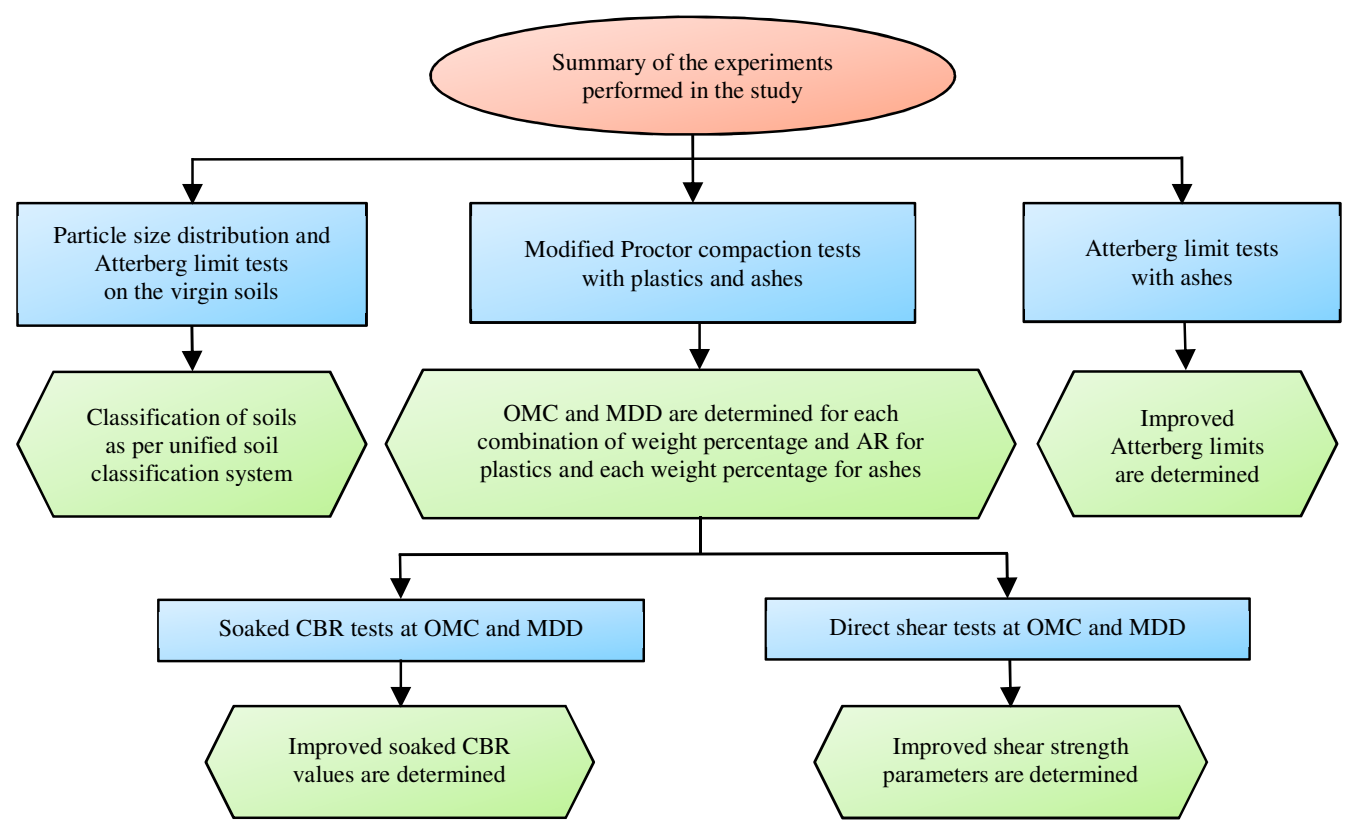

Fig. 1 Experiments performed in the study

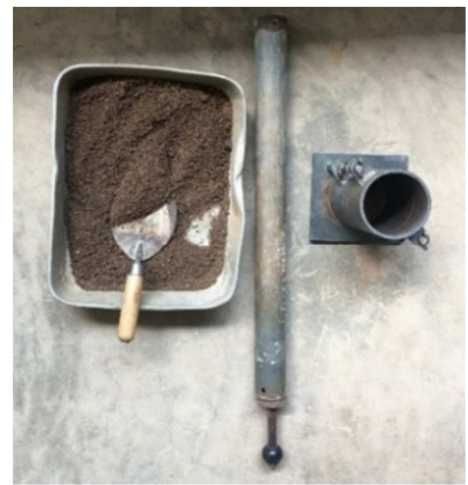

Fig. 2 Modified Proctor compaction test setup

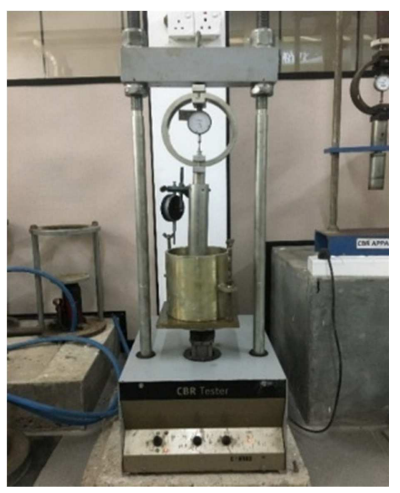

Fig. 3 Soaked CBR test setup

Soils that are significantly cohesionless cannot be made as cylindrical samples by using conventional methods. Moreover, the preparation of samples for conducting direct shear tests is more convenient, quicker, and simpler, as compared to that for triaxial tests. Hence, the direct shear tests are preferred over the triaxial tests in this work and are carried out as per ASTM D3080 [19]. Soaked CBR tests simulate the worst field condition and hence it is preferred for the design purpose. Therefore, the soaked CBR tests are preferred over the unsoaked CBR tests and are carried out as per ASTM D1883 [20]. Fig. 3 shows the soaked CBR test setup. CBR and direct shear tests are performed on the soils with and without the stabilizing agents to analyze the effects of stabilizing agents on CBR and shear strength parameters. CBR and direct shear tests are carried out on the soils at 98\% MDD and its corresponding OMC after adding the plastics with the AR that shows the best improvement in MDD, among all the other ARs for each weight percentage. Similarly, CBR and direct Shear tests are conducted on the soils mixed with the leaf ash mixture in all the considered weight percentages at 98\% MDD and its corresponding OMC.

\section{Results and Discussion}

\subsection{Test results of virgin soils}

Results of the preliminary tests (particle size distribution, Atterberg limits, and specific gravity) and strength tests (modified Proctor compaction, CBR, and direct shear) of the virgin soils are listed in Table 1. Particle size distribution curves of all three soils are shown in Fig. 4. Soils 1, 2, and 3 are classified as poorly graded sand (SP), clayey sand (SC), and poorly graded sand with clay (SP-SC), respectively, as per USCS [21]. 


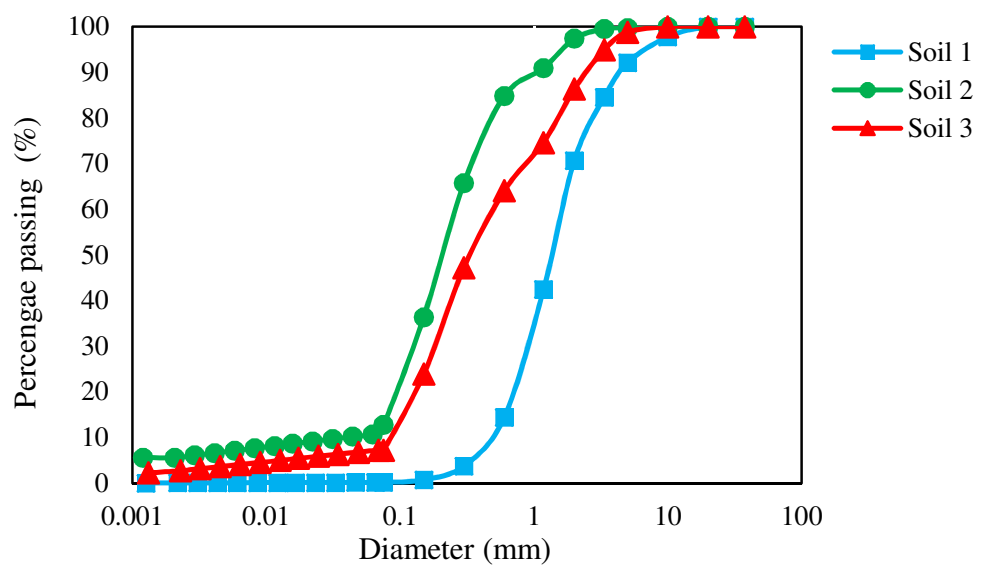

Fig. 4 Particle size distribution curves

Table 1 Results of preliminary and strength tests on virgin soils

\begin{tabular}{|c|c|c|c|c|}
\hline Tests & Properties & Soil 1 (SP) & Soil 2 (SC) & Soil 3 (SP-SC) \\
\hline \multirow{3}{*}{ Atterberg limit test } & Liquid limit (LL) & 18.7 & 26.4 & 28 \\
\cline { 2 - 5 } & Plastic limit (PL) & 13.5 & 16.6 & 20.3 \\
\cline { 2 - 5 } & PI & 5.2 & 9.8 & 7.7 \\
\hline Specific gravity test & Specific gravity $(\mathrm{Gs})$ & 2.66 & 2.71 & 2.68 \\
\hline \multirow{2}{*}{$\begin{array}{c}\text { Modified Proctor } \\
\text { compaction test }\end{array}$} & $\mathrm{MDD}\left(\mathrm{kg} / \mathrm{m}^{3}\right)$ & 1980.5 & 2014.8 & 1919.2 \\
\cline { 2 - 5 } & OMC $(\%)$ & 14.6 & 14.46 & 15.2 \\
\hline \multirow{2}{*}{ Direct shear test } & Cohesion $(\mathrm{kPa})$ & 0.8 & 15.9 & 9.5 \\
\cline { 2 - 5 } & Angle of internal friction $(\phi)$ & 28.5 & 22.1 & 24.6 \\
\hline Soaked CBR test & Soaked CBR $(\%)$ & 18.6 & 11.9 & 13.4 \\
\hline
\end{tabular}

\subsection{Test results of the chemical analysis on seven kinds of leaf ashes}

XRF tests are conducted on the ashes from seven kinds of leaves commonly available in Sri Lanka to find out their chemical compositions. The chemical compositions of those ashes are listed in Table 2. Leaf ashes can be considered pozzolanic material if the summation of the percentage of $\left(\mathrm{SiO}_{2}+\mathrm{Al}_{2} \mathrm{O}_{3}+\mathrm{Fe}_{2} \mathrm{O}_{3}\right)$ exceeds 50\% [22]. From Table 2, it is clear that the leaf ashes of banana, bamboo, teak, Gliricidia sepium, and Thespesia populne show pozzolanic characteristics. The mango leaf ashes and neem leaf ashes do not possess pozzolanic characteristics. Hence, the mixture of leaf ashes is made by mixing the leaf ashes of banana, bamboo, teak, Gliricidia sepium, and Thespesia populne in equal proportion. The specific gravity of the leaf ash mixture used for the study is 2.14 , and the bulk specific gravities of the compacted and uncompacted mixture of leaf ashes are $703.68 \mathrm{~kg} / \mathrm{m}^{3}$ and $595.73 \mathrm{~kg} / \mathrm{m}^{3}$ respectively.

Table 2 Chemical composition of leaf ashes

\begin{tabular}{|c|c|c|c|c|c|c|c|c|c|c|}
\hline Leaf ashes & $\mathrm{SiO}_{2}(\%)$ & $\mathrm{TiO}_{2}(\%)$ & $\mathrm{Al}_{2} \mathrm{O}_{3}(\%)$ & $\mathrm{MnO}(\%)$ & $\mathrm{MgO}(\%)$ & $\mathrm{CaO}(\%)$ & $\mathrm{Na}_{2} \mathrm{O}(\%)$ & $\mathrm{K}_{2} \mathrm{O}(\%)$ & $\mathrm{P}_{2} \mathrm{O}_{5}(\%)$ & $\mathrm{Fe}_{2} \mathrm{O}_{3}(\%)$ \\
\hline Banana & 49.14 & 0.18 & 1.49 & 0.12 & 9.43 & 18.75 & 0.39 & 10.73 & 3.07 & 1.11 \\
\hline Bamboo & 65.21 & 0.25 & 2.21 & 0.06 & 3.72 & 6.58 & 0.45 & 9.53 & 7.98 & 0.94 \\
\hline Mango & 46.7 & 0.06 & 0.31 & 0.07 & 3.73 & 32.88 & 0.25 & 6.38 & 2.55 & 0.14 \\
\hline Neem & 44.89 & 0.01 & 0.23 & 0.04 & 8.54 & 22.31 & 1.98 & 11.65 & 8.97 & 0.76 \\
\hline Teak & 68.34 & 1.07 & 4.98 & 0.07 & 2.56 & 5.64 & 0.76 & 7.86 & 4.43 & 1.96 \\
\hline Gliricidia sepium & 51.54 & 0.05 & 2.31 & 0.15 & 5.87 & 15.53 & 0.65 & 10.86 & 7.86 & 0.65 \\
\hline Thespesia populnea & 48.89 & 0.07 & 1.65 & 0.08 & 6.76 & 18.76 & 0.68 & 9.67 & 8.95 & 1.34 \\
\hline
\end{tabular}

\subsection{Results of modified Proctor compaction tests with the addition of stabilizers}

Fig. 5 shows the MDD variation of soil 1 (SP) with the addition of the plastics in different weight percentages with different ARs as well as the addition of the leaf ash mixture in different weight percentages. The OMC variation of soil 1 (SP) with the addition as described above is shown in Fig. 6. MDD is improved by adding the plastics in the weight percentages 0.5 , 1, 2, and 4 with all the ARs for soil 1 (SP) compared to that in the virgin state. Also, MDD is improved with the addition of the 
leaf ash mixture in 2, 4, 6, and 8 percentages compared to that of the virgin soil 1 . However, the addition of the $8 \%$ plastics with all the ARs and the $10 \%$ leaf ash mixture shows no improvement in MDD for soil 1. From the study by Choudhary et al. [4], the optimum improvement in MDD was observed with the addition of the 4\% plastics with the AR of 3. Nnochiri and Aderinlewo [13] found the best improvement in MDD with the addition of 4\% BALA. However, in this study, the best improvement in MDD is observed with the addition of the $2 \%$ plastics with the AR of 2 at $12.16 \%$ OMC. The second-best improvement in MDD is observed with the addition of the $6 \%$ leaf ash mixture at $12.52 \%$ OMC on soil 1.

Fig. 7 shows the MDD variation of soil 2 (SC) with the addition of the plastics in different weight percentages with different ARs as well as the addition of the leaf ash mixture in different weight percentages. The OMC variation of soil 2 (SC) with the addition as described above is shown in Fig. 8. The addition of the plastics in $0.5,1$, and 2 weight percentages with all four ARs and the leaf ash mixture in all the considered weight percentages shows improvement in MDD of soil 2. Bhattarai et al. [11] and Neopaney et al. [12] found out that the best improvement in MDD was possible with the addition of $0.5 \%$ plastics. However, from this study, the highest MDD is observed with the addition of the $6 \%$ leaf ash mixture at $12.6 \%$ OMC on soil 2 . The best improvement while considering plastics is observed with the addition of the $2 \%$ plastics with the AR of 1 at $10.5 \%$ OMC on soil 2 .

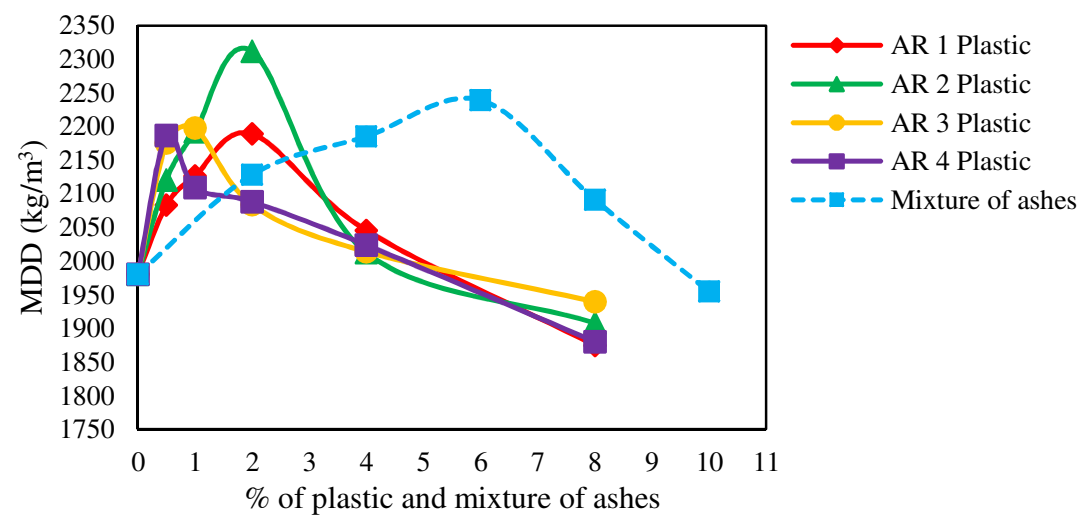

Fig. 5 MDD variation with the stabilizing agents on soil 1

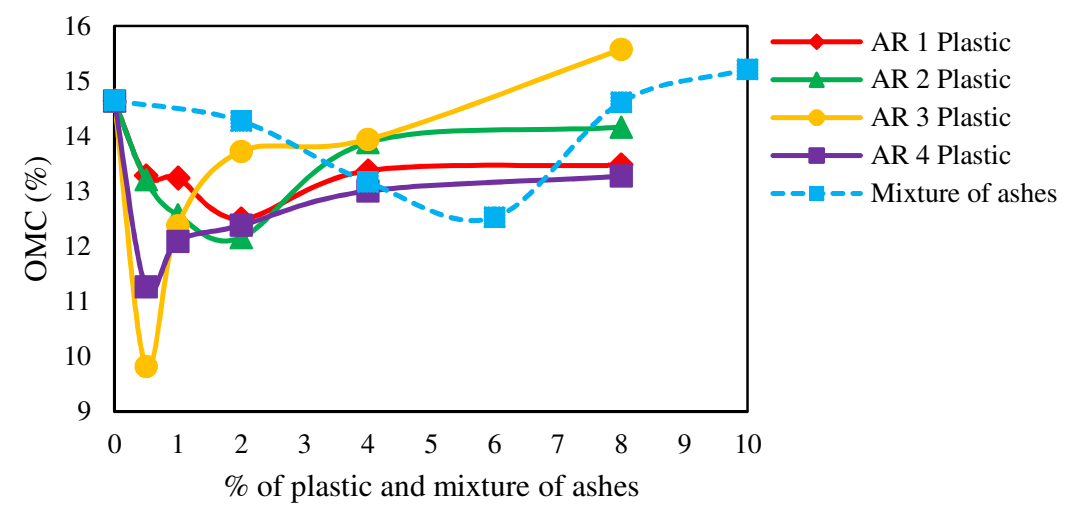

Fig. 6 OMC variation with different additives (plastics and the leaf ash mixture) for soil 1 (SP)

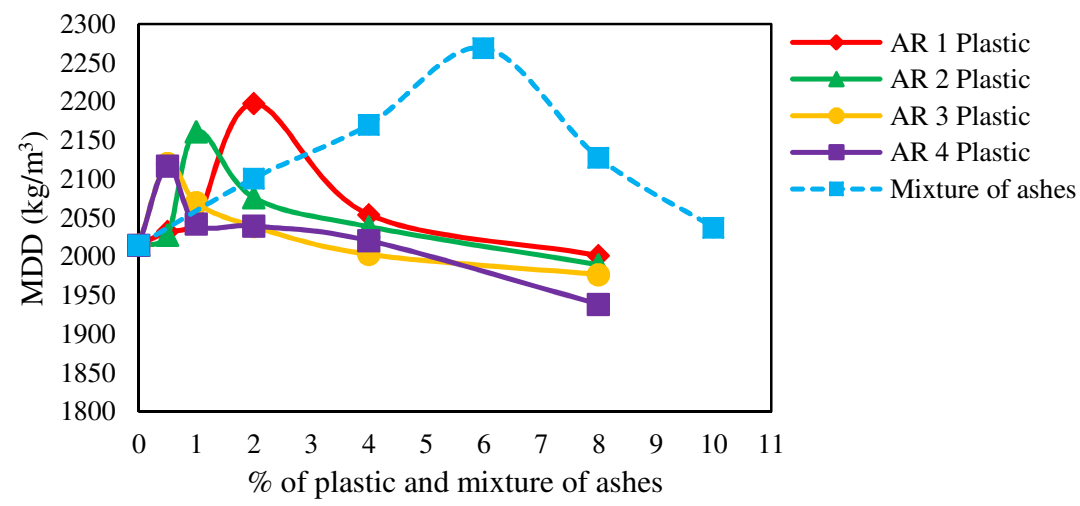

Fig. 7 MDD variation with the addition of stabilizing agents on soil 2 


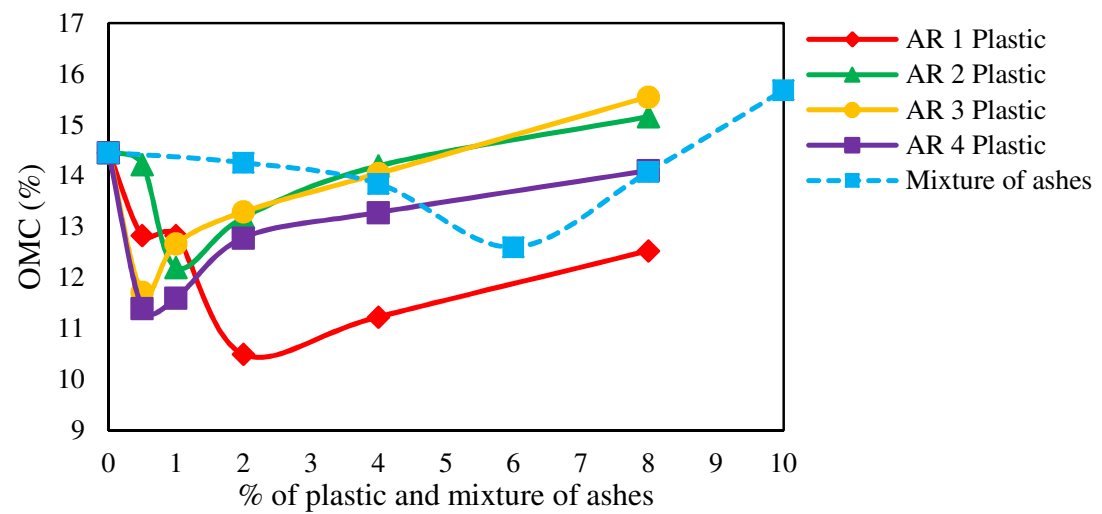

Fig. 8 OMC variation with different additives (plastics and the leaf ash mixture) for soil 2 (SC)

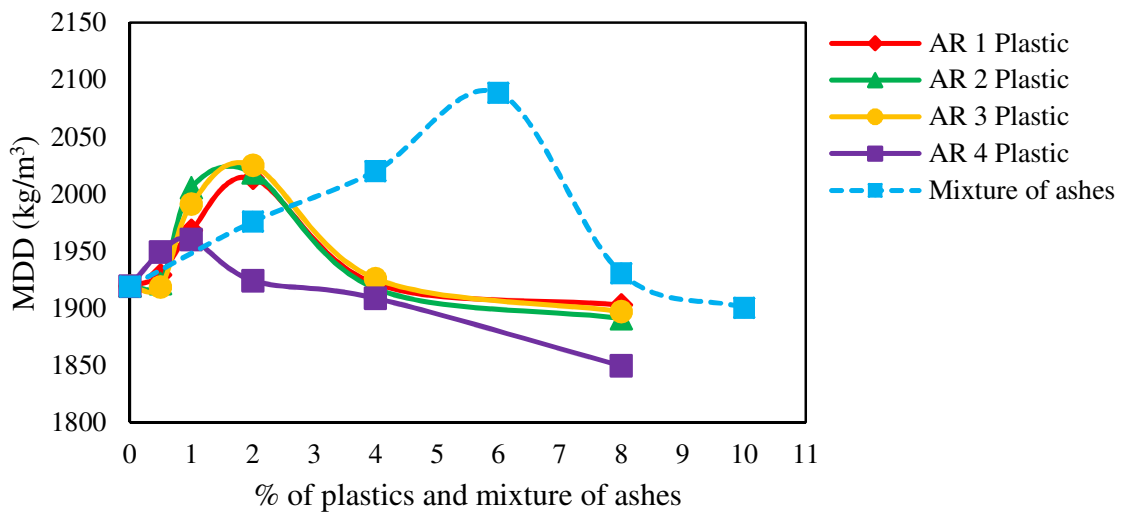

Fig. 9 MDD variation with the addition of stabilizing agents on soil 3

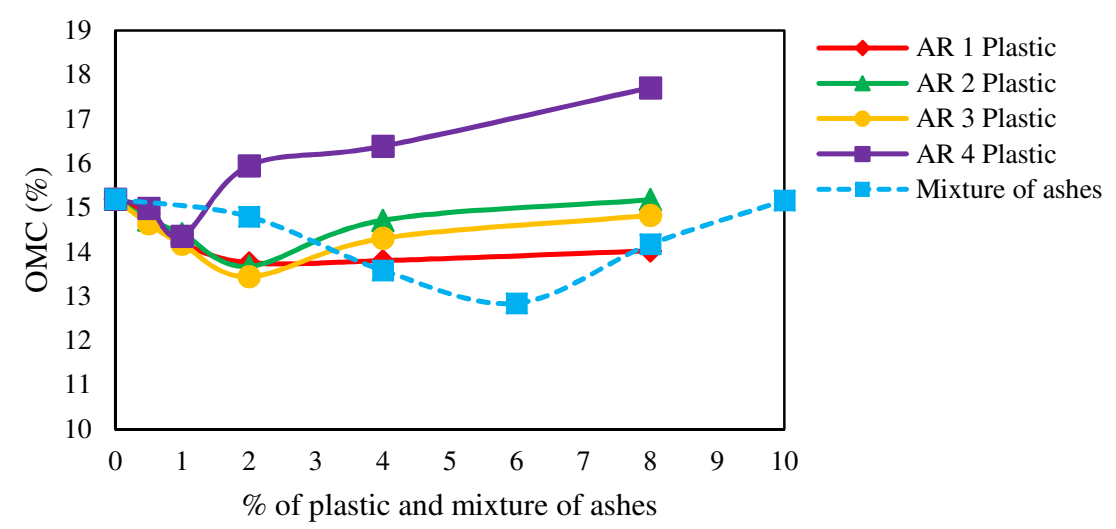

Fig. 10 OMC variation with different additives (plastics and the leaf ash mixture) for soil 3 (SP-SC)

Fig. 9 shows the MDD variation of soil 3 (SP-SC) with the addition of the plastics in different weight percentages with different ARs as well as the addition of the leaf ash mixture in different weight percentages. The OMC variation of soil 3 (SP-SC) with the addition as described above is shown in Fig. 10. Similar to soil 2, the best improvement in MDD for soil 3 is observed with the addition of the $6 \%$ leaf ash mixture at $12.84 \%$ OMC on soil 3 . When the $2 \%$ plastics with the ARs of 1,2 , and 3 are used, the improvement in MDD is quite closer to one another.

While considering the impact of the plastics and the leaf ash mixture on the MDD of all three soils, with the addition of the $0.5,1$, and $2 \%$ plastics with all ARs as well as the 2, 4, 6, and $8 \%$ leaf ash mixture, the MDD of all three soils improves compared to the MDD at the virgin states. This is due to the decrease in the number of voids with the addition of stabilizing agents. This will enhance compaction by reducing OMC and increasing MDD, which indicates the improvement of soils. On the other hand, a drop in the improvement of MDD is observed with the addition of the 8 and $10 \%$ leaf ash mixture and the 4 and $8 \%$ plastics mostly. This is due to the reduction of specific gravity of the soils with the addition of stabilizing agents in high percentages as well as the lack of curing time [13]. 


\subsection{Results of soaked CBR and direct shear tests with the addition of stabilizers}

\subsubsection{Impact of stabilizing agents on soaked CBR}

Figs. 11(a)-(c) show the results obtained from the soaked CBR tests with the addition of the stabilizing agents in different weight percentages on soil 1 (SP), 2 (SC), and 3 (SP-SC), respectively. Fig. 11(a) shows that soaked CBR increases 2.5 times with the addition of the $6 \%$ leaf ash mixture for soil 1 compared to its virgin state. Fig. 11(b) shows that soaked CBR increases more than 3 times for a similar percentage (6\%) of the leaf ash mixture on soil 2 compared to its virgin state Fig. 11(c) shows that soaked CBR increases more than twice at the same leaf ash mixture percentage for soil 3 compared to its virgin state. Amu and Adetuberu [8] also showed that the best improvement in CBR was observed with the addition of 6\% BLA. However, Nnochiri and Aderinlewo [13] found that the optimum improvement in CBR was possible with the addition of 4\% BALA. Figs. 11(a) and 11(c) show that soaked CBR increases more than twice for soils 1 and 3 respectively with the addition of $2 \%$ plastics compared to the virgin states. Fig. 11(b) shows that soaked CBR increases more than thrice with the addition of a similar percentage (2\%) on soil 2 compared to its virgin state. However, Choudhary et al. [4] found out that the best improvement in CBR was possible with the addition of $4 \%$ plastics.

There is improvement in soaked CBR on all three soils with the addition of the leaf ash mixture in all the considered weight percentages compared to that of the three virgin soils. An increase in soaked CBR values with the addition of the leaf ash mixture would be due to the gradual formation of cementitious components between $\mathrm{Ca}(\mathrm{OH})_{2}$ present in the soils and pozzolanic ashes [23]. Due to the interaction of soils and the added plastic strips, there would be a resistance created. Hence, there is improvement in soaked CBR with the addition of plastics [24]. A drop in the improvement of soaked CBR can be noticed with higher weight percentages of the leaf ash mixture on all three soils. This is due to the excess of ashes that are not mobilized in the reaction since the presence of naturally occurring calcium hydroxide in the soils is not significant [25]. The addition of plastics in higher percentages such as $4 \%$ and $8 \%$ causes overlapping; as a result, the interaction of soil particles becomes weaker and ends up with the drop in soaked CBR values [26].

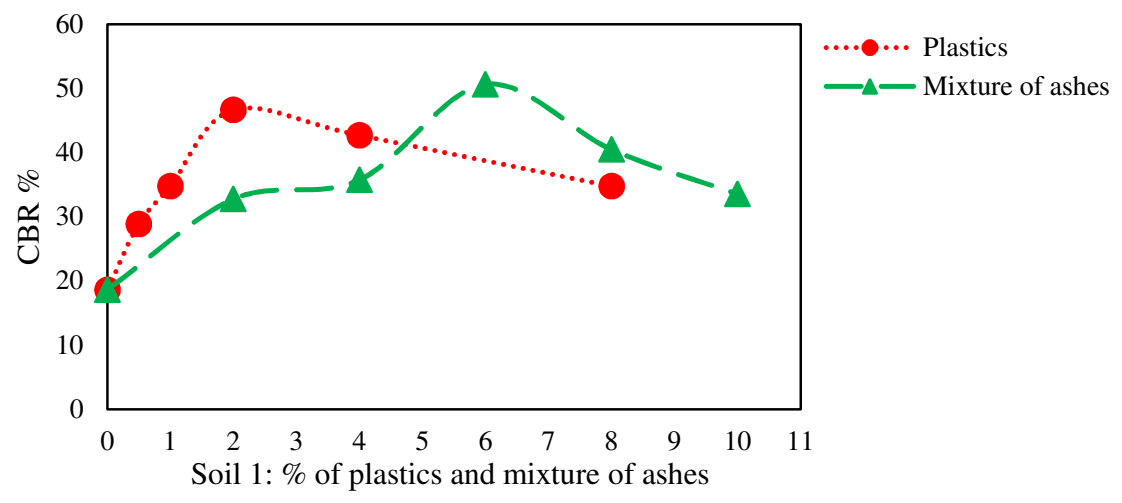

(a) Soaked CBR variation on soil 1

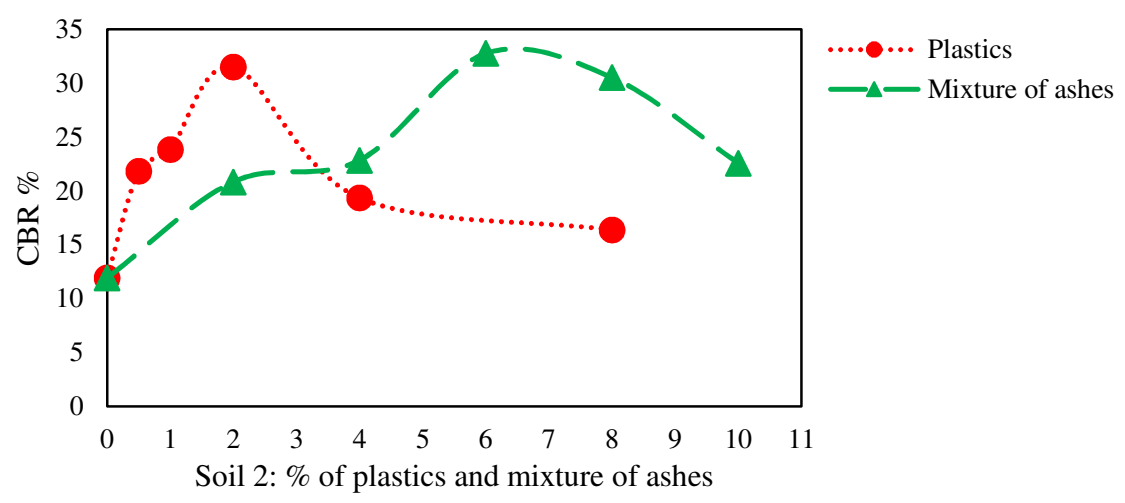

(b) Soaked CBR variation on soil 2

Fig. 11 Soaked CBR variation with the addition of stabilizing agents 


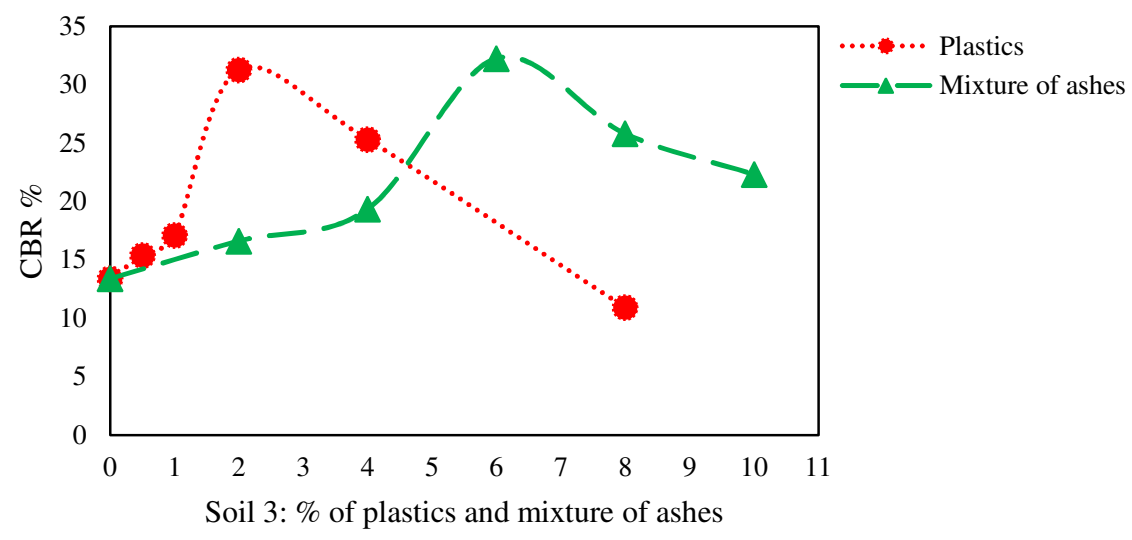

(c) Soaked CBR variation on soil 3

Fig. 11 Soaked CBR variation with the addition of stabilizing agents (continued)

\subsubsection{Impact of stabilizing agents on shear strength parameters}

Tables 3, 4, and 5 show the results obtained from the direct shear tests with the addition of the stabilizing agents in different weight percentages on soils 1,2 , and 3 , respectively. The improvement in the internal angle of friction is noticed with the addition of the plastics in all the weight percentages considered as well as the leaf ash mixture compared to that of the virgin soil 1. The best improvement in the internal angle of friction is observed with the addition of $2 \%$ plastics and the $6 \%$ leaf ash mixture on soil 1. However, there is no significant improvement in the cohesion values with the addition of both stabilizing agents since the clay component of soil 1 is very low.

There is improvement in the internal angle of friction with the additions of both the stabilizing agents in all the weight percentages considered on soil 2 except the $8 \%$ plastics and the $10 \%$ leaf ash mixture. The best improvement in the internal angle of friction is noticed with the addition of the $4 \%$ plastics as well as the $6 \%$ leaf ash mixture, while the addition of the $6 \%$ leaf ash mixture shows the best improvement in cohesion on soil 2.

Optimum improvement in the angle of internal friction and cohesion is noticed with the addition of the $4 \%$ leaf ash mixture on soil 3. Nnochiri and Aderinlewo [13] also found out that the best improvement in shear strength is possible with the addition of $4 \%$ BALA. However, in this study, with the addition of the leaf ash mixture in all the considered weight percentages, there is an improvement in the shear strength parameters for soil 3 compared to its virgin state.

In the case of plastics, the addition of $2 \%$ shows optimum improvement in the angle of internal friction. The addition of fine-sized leaf ash mixture to the soils can flocculate and alter the angularity of the soil particles. This would improve the interlocking and intergranular friction of the soil particles. Due to that, the internal angle of friction values gets improved [27]. In nature, a leaf ash mixture does not show cohesion. However, direct shear tests are conducted at OMC. Hence, the soils mixed with the leaf ash mixture at OMC might show apparent cohesion. Also, there would be some amounts of clay components present in soils 2 and 3. Therefore, pozzolanic actions between the leaf ash mixture and the soils may create a bond. The improvement in cohesion is noticed because of such reasons.

The improvement in the internal angle of frictions is observed with the addition of the plastics in $0.5,1$, and 2 percentages on all three soils. This is due to the increment of friction with the addition of plastics [28]. However, with the addition of a higher amount of plastics such as $8 \%$, the improvement in the angle of internal friction drops. This can be elaborated by the fact that the internal surface area of plastics may increase with the addition of the plastics in higher percentages, resulting in the shear deformation of the soils. However, no considerable improvement in cohesion is observed in all three soils with the addition of plastics since it is non-cementitious. 
Table 3 Variation of shear strength parameters with the addition of stabilizing agents on soil 1 (SP)

\begin{tabular}{|c|c|c|c|c|}
\hline \multirow{2}{*}{ \% of stabilizers } & \multicolumn{2}{|c|}{ Plastics } & \multicolumn{2}{c|}{ Mixture of leaf ashes } \\
\cline { 2 - 5 } & $\begin{array}{c}\text { Angle of } \\
\text { internal friction }(\phi)\end{array}$ & $\begin{array}{c}\text { Cohesion } \\
(\mathrm{kPa})\end{array}$ & $\begin{array}{c}\text { Angle of } \\
\text { internal friction }(\phi)\end{array}$ & $\begin{array}{c}\text { Cohesion } \\
(\mathrm{kPa})\end{array}$ \\
\hline 0 & 28.5 & 0.8 & 28.5 & 0.8 \\
\hline 0.5 & 32.0 & 1.0 & - & - \\
\hline 1 & 34.3 & 1.2 & - & - \\
\hline 2 & 35.1 & 1.3 & 33.5 & 2 \\
\hline 4 & 33.3 & 1.1 & 34.8 & 1.9 \\
\hline 6 & - & - & 35.6 & 1.8 \\
\hline 8 & 30.8 & 0.9 & 34.0 & 1.3 \\
\hline 10 & - & - & 30.2 & 1 \\
\hline
\end{tabular}

Table 4 Variation of shear strength parameters with the addition of stabilizing agents on soil 2 (SC)

\begin{tabular}{|c|c|c|c|c|}
\hline \multirow{2}{*}{$\%$ of stabilizers } & \multicolumn{2}{|c|}{ Plastics } & \multicolumn{2}{c|}{ Mixture of leaf ashes } \\
\cline { 2 - 5 } & $\begin{array}{c}\text { Angle of } \\
\text { internal friction }(\phi)\end{array}$ & $\begin{array}{c}\text { Cohesion } \\
(\mathrm{kPa})\end{array}$ & $\begin{array}{c}\text { Angle of } \\
\text { internal friction }(\phi)\end{array}$ & $\begin{array}{c}\text { Cohesion } \\
(\mathrm{kPa})\end{array}$ \\
\hline 0 & 22.1 & 15.9 & 22.1 & 15.9 \\
\hline 0.5 & 22.5 & 16.4 & - & - \\
\hline 1 & 23.5 & 16.8 & - & - \\
\hline 2 & 24.6 & 17.3 & 23 & 17.8 \\
\hline 4 & 25.7 & 17 & 24.1 & 22.5 \\
\hline 6 & - & - & 27.0 & 25 \\
\hline 8 & 21.1 & 15.8 & 22.3 & 19 \\
\hline 10 & - & - & 18.9 & 17.9 \\
\hline
\end{tabular}

Table 5 Variation of shear strength parameters with the addition of stabilizing agents on soil 3 (SP-SC)

\begin{tabular}{|c|c|c|c|c|}
\hline \multirow{2}{*}{$\%$ of stabilizers } & \multicolumn{2}{|c|}{ Plastics } & \multicolumn{2}{c|}{ Mixture of leaf ashes } \\
\cline { 2 - 5 } & $\begin{array}{c}\text { Angle of } \\
\text { internal friction }(\phi)\end{array}$ & $\begin{array}{c}\text { Cohesion } \\
(\mathrm{kPa})\end{array}$ & $\begin{array}{c}\text { Angle of } \\
\text { internal friction }(\phi)\end{array}$ & $\begin{array}{c}\text { Cohesion } \\
(\mathrm{kPa})\end{array}$ \\
\hline 0 & 24.6 & 9.5 & 24.6 & 9.5 \\
\hline 0.5 & 25.2 & 10.7 & - & - \\
\hline 1 & 27.5 & 11.4 & - & - \\
\hline 2 & 30.1 & 12.5 & 26.7 & 13.9 \\
\hline 4 & 26.9 & 11 & 30.1 & 15.5 \\
\hline 6 & - & - & 28.2 & 15 \\
\hline 8 & 24.8 & 10 & 27.5 & 11 \\
\hline 10 & - & - & 25.1 & 10 \\
\hline
\end{tabular}

\subsection{Impact of stabilizing agents on Atterberg limits}

Table 6 shows the variation of Atterberg limits with the addition of the leaf ash mixture on soils 1, 2, and 3. The addition of the leaf ash mixture in varying percentages causes variation in the liquid limit (LL), plastic limit (PL), and PI of all the soils. The changes in Atterberg limits are mainly due to the exchange of cation, agglomeration, flocculation, and pozzolanic activity [29]. Amu and Adetuberu [8] found out the least PI were obtained at 2-4\% BLA. In this study, the least PI is noticed with the addition of the $4 \%$ leaf ash mixture on soil 1 and the $6 \%$ leaf ash mixture on soils 2 and 3 . A reduction in PI with the 2, 4, and $6 \%$ leaf ash mixture on all the three soils indicates more stable soils with a marked increase in workability.

Table 6 Variation of Atterberg limits with the addition of the leaf ash mixture on all three soils

\begin{tabular}{|c|c|c|c|c|c|c|c|c|c|}
\hline \multirow{2}{*}{ \% of the leaf ash mixture } & \multicolumn{3}{|c|}{ Soil 1 } & \multicolumn{3}{c|}{ Soil 2 } & \multicolumn{3}{c|}{ Soil 3 } \\
\cline { 2 - 11 } & LL & PL & PI & LL & PL & PI & LL & PL & PI \\
\hline 0.0 & 18.7 & 13.5 & 5.2 & 26.4 & 16.6 & 9.8 & 28.0 & 20.3 & 7.7 \\
\hline 2.0 & 19.9 & 15.1 & 4.8 & 23.8 & 17.1 & 6.7 & 26.5 & 20.4 & 6.1 \\
\hline 4.0 & 20.4 & 16.7 & 3.7 & 25.6 & 20 & 5.6 & 25.0 & 19.4 & 5.6 \\
\hline 6.0 & 22.0 & 17.2 & 4.8 & 28.9 & 24.3 & 4.6 & 27.0 & 22.4 & 4.6 \\
\hline 8.0 & 24.0 & 17.3 & 6.7 & 32.3 & 25.5 & 6.8 & 30.2 & 20.9 & 9.3 \\
\hline 10.0 & 28.9 & 18.4 & 10.5 & 35.4 & 25 & 10.4 & 34.3 & 22.5 & 11.8 \\
\hline
\end{tabular}




\section{Conclusions}

The study investigated the effectiveness of using waste plastics and a pozzolanic leaf ash mixture for improving the geotechnical properties of three soils, such as MDD, CBR, shear strength parameters, and Atterberg limits. The comparison between plastics and the leaf ash mixture on different types of soils was done in this study, which was not addressed in any previous studies. It would not be economical to use cement or chemical to improve the geotechnical properties of soils for small projects. Therefore, considering the economical point of view, it would always be better to use waste materials such as plastics and pozzolanic leaf ashes to improve the geotechnical properties of soils. From the study, the following conclusions were made.

(1) Compared to the other combinations of ARs and weight percentages, the addition of the $2 \%$ plastics with the AR of 2 as well as the $6 \%$ leaf ash mixture could more effectively improve MDD and soaked CBR. The optimum improvement in soaked CBR of the stabilized soil was about two to three times more than that of the virgin soil. With the addition of plastics and the leaf ash mixture, the reduction of the soaked CBR values can lead to the reduction of layer thickness in the case of paved structures and can end up with the reduction in construction costs.

(2) The addition of the leaf ash mixture showed noticeable improvement in shear strength parameters whereas the addition of the plastics in most of the considered weight percentages showed considerable improvement in the angle of internal friction.

(3) The PI of all the three soils (with the addition of the $2 \%, 4 \%$, and $6 \%$ leaf ash mixture) was observed to be lower than the PI of the virgin soil. This indicates the improvement in workability and stability of the soils.

Hence, with the addition of plastics and the pozzolanic leaf ash mixture, the geotechnical properties of soil can be improved. This finding would be helpful in geotechnical applications, such as soil stabilization for pavement construction, foundation works, etc.

\section{Acknowledgements}

The authors thank all who assisted with information and testing.

\section{Conflicts of Interest}

The authors confirm hereby there are no any conflicts of interest. The article has been read properly by named authors and there are no other persons who satisfy the criteria for authorship but are not listed.

\section{References}

[1] O. Ilori, C. E. A. Uko, and I. C. Umoh, "Local Geology, Shear Strength Properties and Bearing Capacity of Coastal Plain Sands in Uyo Metropolis, Akwa-Ibom State, Southeastern Nigeria," Journal of Engineering Research and Reports, vol. 8, no. 4, pp. 1-23, December 2019.

[2] G. Pachideh, M. Gholhaki, and O. Rezaifar, "Experimental Study on Engineering Properties and Microstructure of Expansive Soils Treated by Lime Containing Silica Nanoparticles under Various Temperatures," Geotechnical and Geological Engineering, vol. 39, no. 6, pp. 4157-4168, February 2021.

[3] A. G. Norozi, S. Kouravand, and M. Boveiri, "A Review of Using the Waste in Soil Stabilization," International Journal of Engineering Trends and Technology, vol. 21, no. 1, pp. 33-37, November 2015.

[4] A. K. Choudhary, J. N. Jha, and K. S. Gill, "A Study on CBR Behavior of Waste Plastic Strip Reinforced Soil," Emirates Journal for Engineering Research, vol. 15, no. 1, pp. 51-57, February 2010.

[5] J. Kalliyath, J. Joy, J. Paul, and A. M. Vadakkel, "Soil Stabilization Using Plastic Fibers," International Journal of Science Technology and Engineering, vol. 2, no. 12, pp. 487-487, June 2016.

[6] V. Mallikarjuna and T. B. Mani, "Soil Stabilization Using Plastic Waste," International Journal of Research in Engineering and Technology, vol. 5, no. 5, pp. 391-394, May 2016. 
[7] A. Patel, Geotechnical Investigations and Improvement of Ground Conditions, 1st ed., United Kingdom: Woodhead Publishing, 2019.

[8] O. O. Amu and A. A. Adetuberu, "Characteristics of Bamboo Leaf Ash Stabilization on Lateritic Soil in Highway Construction,” International Journal of Engineering and Technology, vol. 2, no. 4, pp. 212-219, 2010.

[9] L. Parker, "A Whopping 91\% of Plastic Isn't Recycled," https://www.nationalgeographic.com/news/2017/07/plastic-produced-recycling-waste-ocean-trash-debris-environment/, December 20, 2018.

[10] S. W. Thakare and S. K. Sonule, "Performance of Plastic Bottle Reinforced Soil," International Journal of Engineering Innovations and Research, vol. 2, no. 3, pp. 207-210, May 2013.

[11] P. Bhattarai, A. V. A. B. Kumar, K. Santosh, T. Manikanta, and K. Tejeswini, "Engineering Behavior of Soil Reinforced with Plastic Strips," International Journal of Civil, Structural, Environmental, and Infrastructure Engineering Research and Development, vol. 3, no. 2, pp. 83-88, June 2013.

[12] M. Neopaney, K. W. Ugyen, S. Tenzin, and K. S. Chamberlin, "Stabilization of Soil by Using Plastic Wastes," International Journal of Emerging Trends in Engineering and Development, vol. 2, no. 2, pp. 461-466, March 2012.

[13] E. S. Nnochiri and O. O. Aderinlewo, "Geotechnical Properties of Lateritic Soil Stabilized with Banana Leaves Ash," FUOYE Journal of Engineering and Technology, vol. 1, no. 1, pp. 116-119, September 2016.

[14] O. Elijah, "Comparison between Strength Properties of Lateritic Soils Stabilized with Banana Leaf Ash and Oil Palm Frond Ash," International Research Journal of Innovations in Engineering and Technology, vol. 3, no. 1, pp. 20-23, January 2019.

[15] H. Xiao, F. Zhang, R. Liu, R. Zhang, Z. Liu, and H. Liu, "Effects of Pozzolanic and Non-Pozzolanic Nanomaterials on Cement-Based Materials," Construction and Building Materials, vol. 213, pp. 1-9, July 2019.

[16] Standard Test Methods for Particle-Size Distribution (Gradation) of Soils Using Sieve Analysis, ASTM D6913/D6913M, 2017.

[17] Standard Test Methods for Liquid Limit, Plastic Limit, and Plasticity Index of Soils, ASTM D4318, 2017.

[18] Standard Test Methods for Laboratory Compaction Characteristics of Soil Using Modified Effort, ASTM D1557, 2012.

[19] Standard Test Method for Direct Shear Test of Soils under Consolidated Drained Conditions, ASTM D3080, 2004.

[20] Standard Test Method for California Bearing Ratio (CBR) of Laboratory-Compacted Soil, ASTM D1883, 2016.

[21] Standard Practice for Classification of Soils for Engineering Purposes (Unified Soil Classification System), ASTM D2487, 2017.

[22] Standard Test Methods for Sampling and Testing Fly Ash or Natural Pozzolans for Use in Portland-Cement Concrete, ASTM C311/C311M, 2018.

[23] F. O. Okafor and U. N. Okonkwo, "Effects of Rice Husk Ash on Some Geotechnical Properties of Lateritic Soil," Leonardo Electronic Journal of Practices and Technologies, vol. 15, pp. 67-74, July-December 2009.

[24] H. J. A. Hassan, J. Rasul, and M. Samin, "Effects of Plastic Waste Materials on Geotechnical Properties of Clayey Soil," Transportation Infrastructure Geotechnology, vol. 8, no. 3, pp. 390-413, January 2021.

[25] S. Adhikary and K. Jana, "Potentials of Rice-Husk Ash as a Soil Stabilizer," International Journal of Latest Research in Engineering and Technology, vol. 2, no. 2, pp. 40-48, February 2016.

[26] A. K. Choudhary, J. N. Jha, K. S. Gill, and S. K. Shukla, "Utilization of Fly Ash and Waste Recycled Product Reinforced with Plastic Wastes as Construction Materials in Flexible Pavement," Geo-Congress, pp. 3890-3902, February 2014.

[27] C. C. Ikeagwuani, D. C. Nwonu, C. Eze, and I. Onuoha, "Investigation of Shear Strength Parameters and Effect of Different Compactive Effort on Lateritic Soil Stabilized with Coconut Husk Ash and Lime," Nigerian Journal of Technology, vol. 36, no. 4, pp. 1016-1021, January 2018.

[28] A. Kumar and H. Vageesh, "Effect of Discarded Plastic Waste as Stabilizer on Engineering Properties of Cohesive Soil," International Journal of Engineering Technology Science and Research, vol. 4, no. 12, pp. 779-786, December 2017.

[29] B. D. Nath, G. Sarkar, S. Siddiqua, M. Rokunuzzaman, and M. Islam, "Geotechnical Properties of Wood Ash-Based Composite Fine-Grained Soil,” Advances in Civil Engineering, vol. 2018, 9456019, 2018.

Copyright $(\subset$ by the authors. Licensee TAETI, Taiwan. This article is an open access article distributed under the terms and conditions of the Creative Commons Attribution (CC BY-NC) license (https://creativecommons.org/licenses/by-nc/4.0/). 